\title{
Structural basis for the pathophysiology of lipoprotein(a) in the athero-thrombotic process
}

\section{E. Anglés-Cano}

Correspondence

E. Anglés-Cano

INSERM U. 143, Hôpital de Bicêtre

84, rue du Général-Leclerc

F-94276-Cedex, Bicêtre

France

Fax: +33 (1) 46719472

E-mail: angles@infobiogen.fr

Presented at the XII Annual Meeting of the Federação de Sociedades de Biologia Experimental, Caxambu, MG, Brasil, August 27-30, 1997.

Research supported by INSERM (No. 4N001B) and the Ministère de la Recherche (No. ACC-SV9).

......................

Received August 14, 1997 Accepted August 25, 1997
Institut National de la Santé et de la Recherche Médicale (INSERM), U. 143, Centre

Hospitalier Universitaire de Bicêtre, Université de Paris-Sud, Paris, France

\begin{abstract}
Lipoprotein $\mathrm{Lp}(\mathrm{a})$ is a major and independent genetic risk factor for atherosclerosis and cardiovascular disease. The essential difference between $\mathrm{Lp}(\mathrm{a})$ and low density lipoproteins (LDL) is apolipoprotein apo(a), a glycoprotein structurally similar to plasminogen, the precursor of plasmin, the fibrinolytic enzyme. This structural homology endows $\mathrm{Lp}$ (a) with the capacity to bind to fibrin and to membrane proteins of endothelial cells and monocytes, and thereby to inhibit plasminogen binding and plasmin generation. The inhibition of plasmin generation and the accumulation of $\mathrm{Lp}(\mathrm{a})$ on the surface of fibrin and cell membranes favor fibrin and cholesterol deposition at sites of vascular injury. Moreover, insufficient activation of TGF- $\beta$ due to low plasmin activity may result in migration and proliferation of smooth muscle cells into the vascular intima. These mechanisms may constitute the basis of the athero-thrombogenic mode of action of $L p(a)$. It is currently accepted that this effect of $L p(a)$ is linked to its concentration in plasma. An inverse relationship between $\mathrm{Lp}$ (a) concentration and apo(a) isoform size, which is under genetic control, has been documented. Recently, it has been shown that inhibition of plasminogen binding to fibrin by apo(a) is also inversely associated with isoform size. Specific point mutations may also affect the lysine-binding function of apo(a). These results support the existence of functional heterogeneity in apolipoprotein(a) isoforms and suggest that the predictive value of $L p(a)$ as a risk factor for vascular occlusive disease would depend on the relative concentration of the isoform with the highest affinity for fibrin.
\end{abstract}

\section{Introduction}

Atherosclerosis is a complex silent process characterized by amorphous lipid accumulation in the intima, which may result in coronary heart disease. Atherosclerotic plaque rupture with superimposed thrombosis is present in coronary arteries in $80-90 \%$ of patients with fatal ischemic cardiac events
Key words

- Atherosclerosis

- Apolipoprotein(a)

- Thrombosis

- Atheroma

- Plasminogen

- Lipoprotein

- Fibrin

- Fibrinolysis
(1). Thrombosis results from an impaired antithrombotic response to vascular injury. Factors injurious to the arterial intima may alter its selective permeability, favor the accumulation of lipids with formation of fatty streaks, and allow deposition of microthrombi. Repair of early lesions is basically a healing process but beyond a certain stage the reparative process becomes largely pro- 
liferative with multiplication of smooth muscle cells, macrophage recruitment with cholesterol deposition and organization of mural thrombi (2); repeated injury and an abnormal repair response contribute to the progression from early to advanced atherosclerotic lesions.

\section{The lipoprotein(a) connection in atherosclerosis and thrombosis}

Atherosclerosis is a multifactorial disease: high serum cholesterol concentrations carried by low density lipoproteins (LDL), high blood pressure and cigarette smoking have been established as major risk factors for coronary heart disease. A number of epidemiological and clinical studies have now established that high plasma concentrations of the lipoprotein Lp(a), an LDL-like particle discovered by Berg in 1963 (3), is also a major and independent risk factor for myocardial infarction. $\mathrm{Lp}(\mathrm{a})$ is a complex particle composed of a lipid core and two disulfide-linked subunits: apolipoprotein B100 and apolipoprotein apo(a) (Figure 1). The lipid core and apo B-100 of Lp(a) are shared with LDL; in contrast, the apo(a) glycoprotein confers its characteristic properties on Lp(a). Apo(a) shows a high degree of homology with plasminogen, the precursor of the fibrinolytic enzyme plasmin.

The mechanism by which $\mathrm{Lp}$ (a) may favor atherosclerosis is still a matter of debate but the fact that $\mathrm{Lp}(\mathrm{a})$ has both LDL and plasminogen-like moieties suggests that $L p(a)$ may constitute a link between the processes of atherosclerosis and thrombosis. Indeed, $\mathrm{Lp}$ (a) and fibrin have been identified in atherosclerotic plaques (4-6); moreover, in transgenic mice expressing human apo(a), apo(a) co-localizes with lipid deposition on the arterial wall (7). In order to understand the basis of this connection we will briefly review the plasminogen activation system and consider recent evidence indicating that $\mathrm{Lp}(\mathrm{a})$ is a major risk factor for coronary heart disease.

\section{Plasminogen and apolipoprotein(a): homologous proteins with opposite effects}

Plasminogen is a single-chain glycoprotein of Mr 93,000 secreted by the liver and found in plasma at a concentration of 1.5 to $2 \mu \mathrm{mol} / \mathrm{l}$. It consists of 791 amino acid residues arranged in two types of domains with functional autonomy: the kringle modules and the serine-proteinase region (Figure 1). Kringles are sequences of 80-90 amino acids arranged in a triple-loop tertiary structure rigidly stabilized by three disulfide bridges (8). The kringle structure was first described in prothrombin and is found in several copies in proteins that evolved from a common ancestral gene, i.e., plasminogen, apo(a) and hepatocyte growth factors. The kringle do-
Figure 1 - Structural homologies between apolipoprotein(a) and plasminogen. Lp(a) shares its lipid composition and apolipoprotein B-100 with low density lipoproteins (LDL). The characteristic feature of $L p(a)$ is the presence of a plasminogen-like apolipoprotein apo(a). This glycoprotein consists of a variable number of copies of kringle 4 and single copies of kringle 5 and the serine-proteinase region of plasminogen.

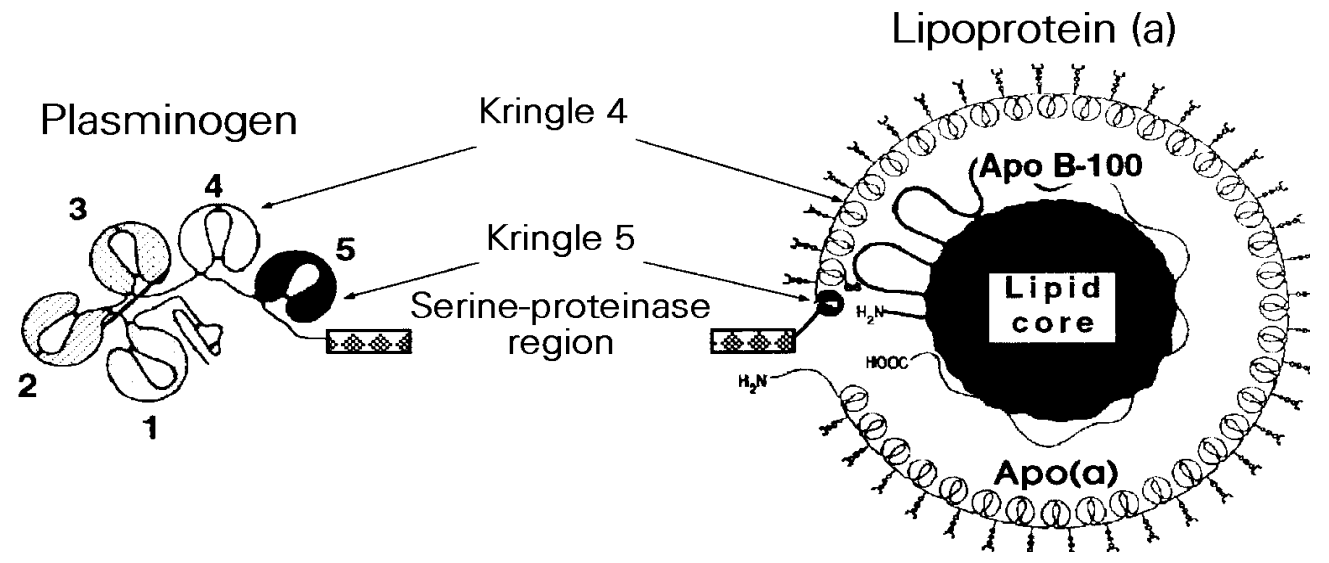


mains of plasminogen, designated 1 to 5 , differ from each other and are connected to the proteinase domain by a sequence adjacent to the activation cleavage site $\operatorname{Arg}_{561^{-}}$ $\mathrm{Val}_{562}$. The serine-proteinase domain contains the active catalytic center $\left(\mathrm{Ser}_{741}, \mathrm{His}_{603}\right.$, $\left.\mathrm{Asp}_{646}\right)$ and is located in the carboxy-terminal region $\left(\mathrm{Val}_{562}-\mathrm{Asn}_{791}\right)$, whereas the amino-terminal region $\left(\mathrm{Glu}_{1}-\mathrm{Arg}_{561}\right)$ bears the five kringle domains and an amino-terminal peptide of 77 residues $\left(\mathrm{Glu}_{1}-\mathrm{Lys}_{77}\right)$ that may be released by plasmin. Thus, native plasminogen possesses a glutamic acid as the amino-terminal residue (Glu-plasminogen), while the corresponding residue in the plasmin-cleaved form is lysine (Lys-plasminogen). Lys-plasminogen is not normally found in human plasma.

Kringles 1 and 4 of plasminogen contain a functional subsite supported primarily by amino acid residues of the inner loop. Since this subsite binds to lysine residues of fibrin and cell membrane proteins it has been termed lysine-binding site or LBS. The structure of this subsite, an ionic dipole with the anionic and cationic sites positioned at opposite ends of a hydrophobic trough, has been well defined (9). In both kringle 1 and kringle 4, the anionic center is constituted by $\mathrm{Asp}_{55}$ and Asp $_{57}$ while the cationic center is mainly represented by $\operatorname{Arg}_{34}$ and $\operatorname{Arg}_{71}$ in kringle 1, and by $\operatorname{Lys}_{35}$ and $\operatorname{Arg}_{71}$ in kringle 4; the distance between $\operatorname{Arg}_{71}$ and $\operatorname{Asp}_{57}(6.8 \AA)$ corresponds closely to the separation of the zwitterionic charges in lysine or in 6aminohexanoic acid, a lysine analogue. The elongated hydrophobic depression of the kringle is lined with aromatic residues that interact with the methylene groups of lysine located between the zwitterionic charges. The specific interactions between lysine residues in fibrin or cell membrane proteins and the lysine-binding subsites in kringles 1 and 4 of plasminogen allow plasminogen binding and activation.

Amino acid sequence analysis and cDNA cloning $(10,11)$ have established that apo(a) contains a variable number of kringle domains that share $61-75 \%$ homology with kringle 4 of plasminogen. The kringle 4-like repeats of apo(a) are followed by a single copy of plasminogen kringle 5 and a protease domain that shares $94 \%$ homology with the corresponding domain of plasminogen. Kringle 4 copies of plasminogen in apo(a) are similar but not identical and have been classified into 10 different types (12) (Figure 2). Kringle 4 type 2 presents the lowest degree of homology with plasminogen kringle 4 and has no functional LBS; the number of this type of kringle in apo(a) is variable and gives rise to a series of apo(a) isoforms that contribute to the heterogeneity of $L p(a)$ : a total of 34 apo(a) alleles and glycoproteins with molecular masses ranging from $~ 300$ to $\sim 800 \mathrm{kDa}$ have been identified by protein (13) and cDNA (14) analysis. The other nine kringle types are present as single copies in all isoforms; kringle 4 type 9 possesses an additional cysteine residue that ensures the covalent binding between apo(a) and apo B-100 and thereby the formation of the Lp(a) particle. Sequence comparison and molecular modeling (15) have shown that a lysine-binding pocket similar to that of plasminogen kringle 4 is present in kringle

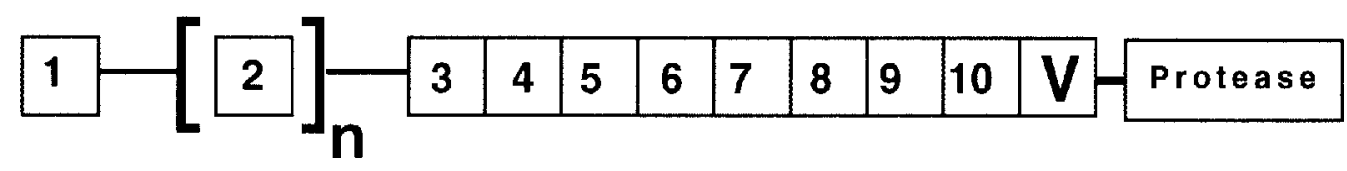

Figure 2 - Representation of the cDNA sequence of human apolipoprotein(a). The apo(a) gene contains a hypervariable region encoding a variable number $(n=1$ to $\sim 40$ ) of kringles 4 type 2 that determines the existence of several apo(a) isoforms. The other kringle 4 types (1 and 3 to 10) and kringle $5(\mathrm{~V})$ are present as single copies. Some of these kringle 4 types endow apo(a) with lysine-fibrin binding properties similar to those of plasminogen. 
4 type 10 of apo(a) (kringle 37 of the original apo(a) cloned by McLean et al. (10)) and that slightly modified LBS are present in kringle 4 types 5 to 8 (32 to 35 according to McLean et al.); these kringle copies may confer binding capabilities similar to those of plasminogen on apo(a). However, the Arg-Val residues of the activation cleavage site in plasminogen have been replaced by Ser-Ile in apo(a), a substitution that impairs recognition of apo(a) by plasminogen activators. Thus, binding of apo(a) instead of plasminogen to fibrin and cell surfaces may result in a diametrically opposed effect, i.e., inhibition of the generation of plasmin (Figure 3).

\section{Inhibition of the generation of plasmin, the major mechanism of action of $\operatorname{Lp}(\mathrm{a})$}

Initial limited degradation of the surface of fibrin by plasmin unveils carboxy-terminal lysine residues and increases the local concentration of plasminogen, a process that amplifies and accelerates the degradation of fibrin. In a plasma milieu, the progression of such a process is markedly influenced by $\alpha_{2}-$ antiplasmin, the specific plasmin inhibitor, which limits the number of carboxy-terminal lysine residues and thereby the amount of bound plasminogen $(16,17)$. On the other hand, the blockade of such residues by iso-
Figure 3 - Plasminogen activation by t-PA on fibrin and by prourokinase on cell surfaces is the major mechanism of defense against thrombosis. Its inhibition by $L p(a)$ constitutes the major mechanism of the athero-thrombogenic effect of this lipoparticle.

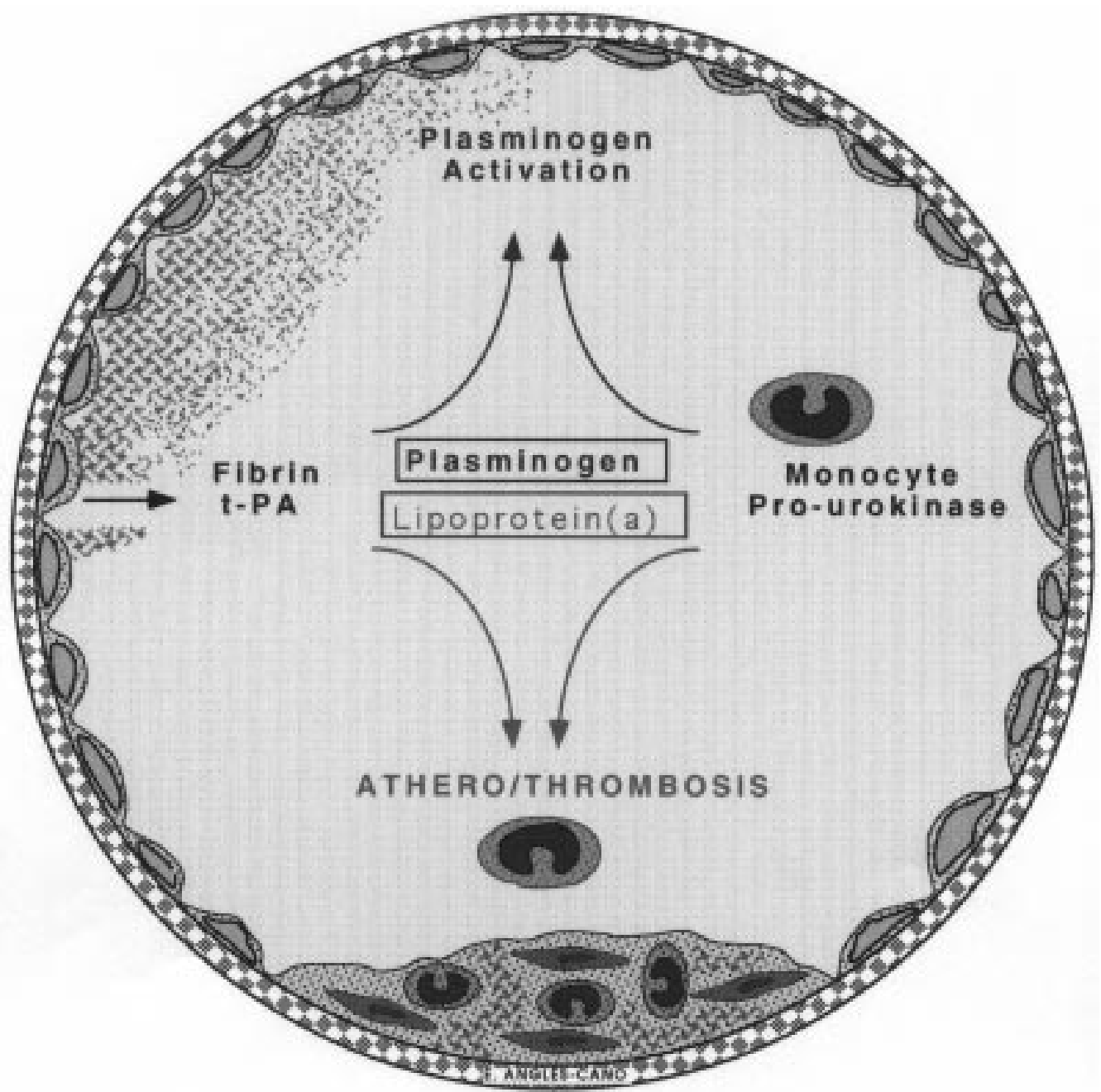


lated plasminogen kringle 4 has been shown to interfere competitively with clot lysis by a mechanism involving binding to lysine-fibrin residues (18). Since the kringle domains behave as autonomous functional structures, the presence in apo(a) of kringle modules structurally related to those of plasminogen may result in analogous interactions with lysine residues of fibrin and cell membranes.

The effect of $L p(a)$ on plasminogen binding to fibrin and cell surfaces has been studied by several groups (19-23). A number of experimental in vitro studies resulted in convincing evidence that $\mathrm{Lp}$ (a) binds to the fibrin surface and cell membranes and thereby competes with plasminogen, inhibiting its activation $(24,25)$. Such unique behavior was attributed to the fibrin-binding properties conferred by the kringle 4 repeats of apo(a) (26). Thus, $L p(a)$ interferes with the evolution of fibrinolysis on the surface of fibrin, endothelial cells, monocytes and platelets through binding of apo(a), an eternal zymogen that decreases the local concentration of plasminogen and cannot be transformed into an active enzyme. Most of the effects of $L p(a)$ such as persistence of fibrin deposits, accumulation of cholesterol and proliferation of smooth muscle cells in the intima are related to a decrease in plasmin activity (Figure 3).

Hypofibrinolysis and cholesterol accumulation are a direct consequence of the presence of $L p(a)$ on the surface of fibrin and cell membranes: apo(a) inhibits plasmin formation and the LDL components favor cholesterol accumulation (Figure 4).

Growth and proliferation of vascular smooth muscle cells are inhibited by active TGF- $\beta$, a growth factor secreted in latent form and activated by plasmin (27). It has been recently shown that $L p(a)$ inhibits the generation of TGF- 3 (28) and that the generation of plasmin and thereby the activation of TGF- $\beta$ are decreased in transgenic mice expressing human apo(a) (29). Insufficient activation of TGF- $\beta$ may result in migration and proliferation of smooth muscle cells into the intima, an important mechanism in atheroma plaque formation. The pathophysiological importance of this mechanism in vivo in other animal models needs further confirmation.

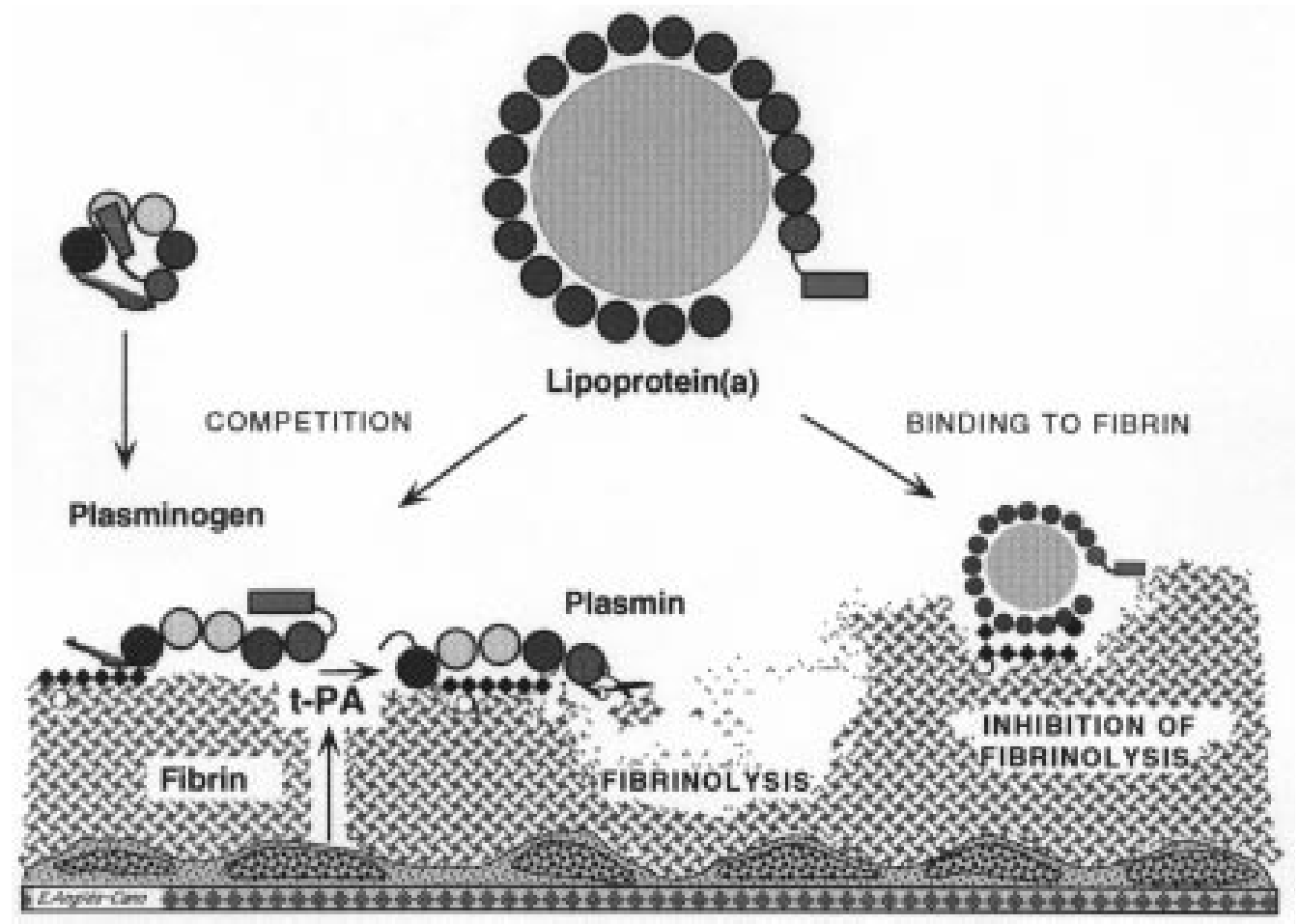

Figure 4 - Competitive inhibition of the binding of plasminogen by $L p(a)$. Inhibition of plasmin generation results in accumulation of fibrin, cholesterol and smooth muscle cells on the vascular wall. 


\section{Other athero-thrombogenic mechanisms of $\operatorname{Lp}(\mathrm{a})$}

Modification of protein synthesis. Lp(a) may stimulate the expression of PAI-1 and inhibit the synthesis of t-PA by endothelial cells in culture (30,31). Thus, inhibition of $t-$ PA by PAI-1 and low t-PA antigen levels may enhance $L p(a)$-dependent hypofibrinolysis by decreasing the amount of t-PA available for the activation of plasminogen.

Binding of $L p(a)$ to extracellular matrix components. Recent reports suggest that $\mathrm{Lp}$ (a) and recombinant apo(a) display high affinity for fibronectin and that $L p(a)$ may form complexes with proteoglycans or glycosaminoglycans of the extracellular matrix $(32,33)$. These interactions are not related to the lysine-binding function of kringle 4 and may contribute to the accumulation of $\operatorname{Lp}(\mathrm{a})$ in the vascular wall.

Oxidation of $\operatorname{Lp}(a)$. The $\mathrm{Lp}(\mathrm{a})$ and $\mathrm{LDL}$ particles are sensitive to oxidative processes. Phagocytosis of oxidized Lp(a) and LDL particles results in the formation of foam cells $(34,35)$. Antioxidants such as probucol and vitamins $\mathrm{C}, \mathrm{E}$ and $\mathrm{B}$-carotenes may prevent such reactions.

Figure 5 represents an overall view of these different mechanisms.

\section{Antifibrinolytic activity of apolipoprotein(a) in vivo}

Most clinical studies have failed to demonstrate that high levels of $L p(a)$ decrease systemic fibrinolysis $(36,37)$. To date there is no definitive evidence that $\mathrm{Lp}(\mathrm{a})$ interferes with plasminogen binding and activation in vivo. Scarce evidence has been obtained from a few experimental studies. Occlusive arterial thrombosis with incorporation of $\mathrm{Lp}(\mathrm{a})$ into damaged arterial segments was observed in cynomolgous monkeys with high plasma Lp(a) levels (38). Biemond et al. (39) studied the effect of a recombinant form of apo(a) on endogenous and t-PAmediated lysis in an in vivo model of experimental thrombosis; endogenous thrombolysis but not t-PA-induced lysis was significantly reduced in the presence of apo(a). In contrast, transgenic mice that express hu-
Figure 5 - General scheme representing different modes of action of $L p(a)$ in the vascular wall. Inhibition of plasmin generation may be further enhanced by modifications of the synthesis of t-PA and PAI-1. Oxidized Lp(a) may contribute to the formation of foam cells by macrophages.

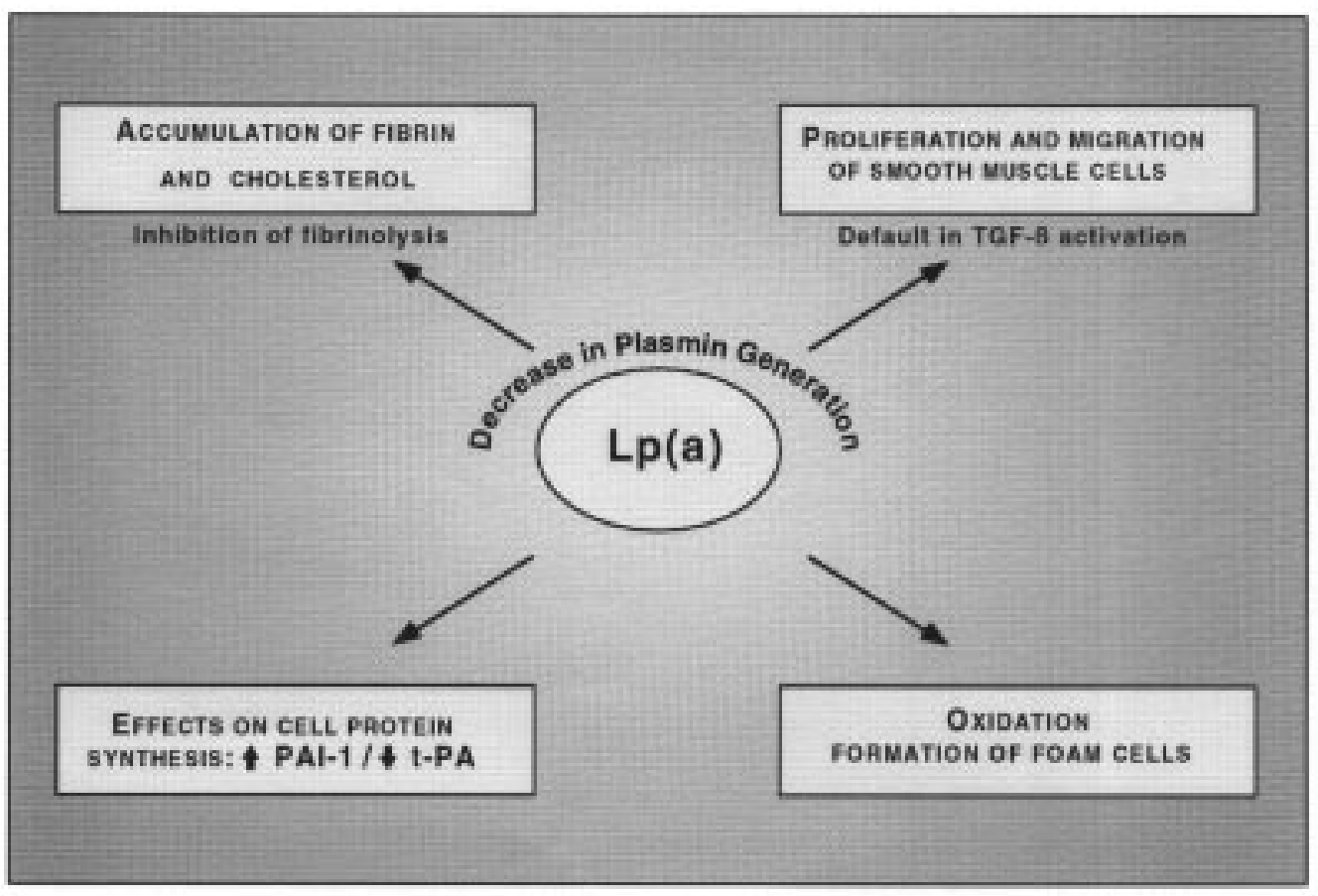


man apo(a) have been shown to exhibit reduced t-PA-induced lysis of pulmonary emboli produced by injection of human platelet-rich plasma clots (40). However, in these experiments the role of PAI- 1 in the inhibition of the reduced doses of t-PA used was not ruled out. These studies strongly suggest that apo(a) may decrease fibrinolysis in vivo. The existence of such a potential pathophysiological mechanism and its relevance to the development of athero-thrombosis are supported by the fact that high Lp(a) levels associated with cardiovascular disease are genetically determined.

\section{Genetic polymorphism and functional heterogeneity of $\operatorname{Lp}(\mathrm{a})$}

The absence of clinical or biological signs of disease in the presence of low or undetectable levels of $L p(a)$, and the existence of an important polymorphism of apo(a) indicative of a low pressure selection suggest that $\mathrm{Lp}$ (a) may not be a vital biological factor. In contrast, a number of retrospective studies have shown that high circulating levels of this lipoparticle are associated with a high risk for cardiovascular and cerebrovascular diseases in young adults ( $<60$ years old). Recent prospective studies have confirmed these observations (41-45) (Table 1). It is now well recognized that the circulating concentration of $\mathrm{Lp}(\mathrm{a})$ is mainly regulated by the apo(a) gene (46). The size of each allele varies as a function of the number of repetitive sequences encoding kringle 4 type 2 (a total of 34 isoforms have been identified by cDNA (14) and protein (13) analysis). In general, the smaller this hypervariable region and therefore the size of the apo(a) isoform, the higher the plasma concentration of $L p(a)$. The question is therefore to know whether the cardiovascular risk associated with $L p(a)$ is linked to apo(a) isoforms of low molecular mass. Recent experimental and clinical evidence provides arguments favoring this hypothesis.

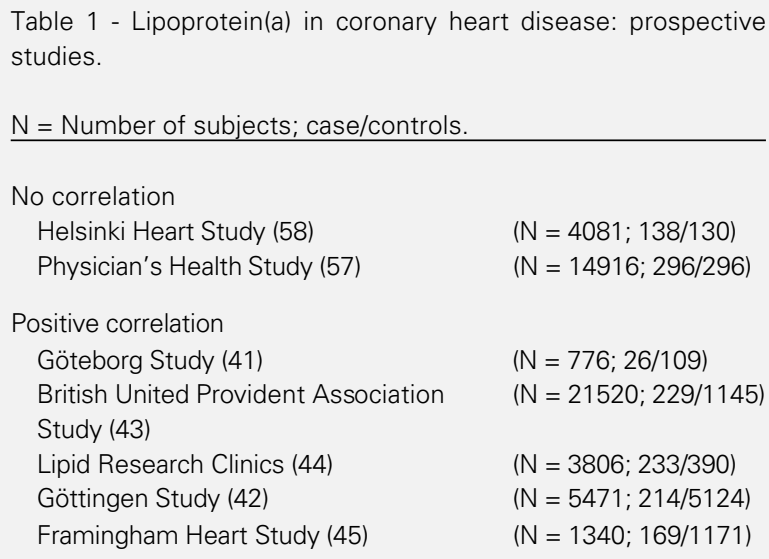

Indeed, a difference in the distribution of apo(a) isoforms between patients with atherosclerosis and a control population has been recently reported (47-49). Low molecular mass isoforms (B, S1 and S2 according to the nomenclature of Utermann (49)) were found more frequently in subjects with high $\mathrm{Lp}$ (a) concentrations and a history of myocardial infarction or intermittent claudication. Thus, short apo(a) alleles may favor atherogenesis by increasing the concentration of $\mathrm{Lp}(\mathrm{a})$. However, a difference in allele distribution between patients at risk and controls is not always observed, and the inverse relationship between apo(a) size and $\mathrm{Lp}(\mathrm{a})$ concentration is not linear, thus suggesting the existence of a functional diversity among apo(a) isoforms. Indeed, some plasmas with a high $L p(a)$ concentration may fail to induce a decrease in fibrinolysis (50). In such case, at similar concentrations of plasminogen and $L p(a)$, it is the functional behavior of apo(a) that may determine the inhibition of plasminogen binding.

Since the atherogenic potential of $\operatorname{Lp}(\mathrm{a})$ is related to the lysine-binding properties conferred by the kringle 4 repeats of apo(a), we have recently explored the possibility that $L p(a)$ phenotypes may have different functional properties with regard to their affinity for fibrin. We demonstrated that $\mathrm{Lp}(\mathrm{a})$ particles from homozygous subjects containing a single, distinct isoform of apo(a) dis- 
play different affinities for fibrin as a function of their size; this finding suggests that the variable number of kringles in apo(a) influences its ability to bind to fibrin (51). Thus, isoforms of low molecular mass showing the highest affinity for fibrin are the best competitor for plasminogen and are epidemiologically related to a higher cardiovascular risk (49-51). The main structural difference between isoforms almost certainly reflects a variable number of kringle 4-like repeats of type 2; kringle 4 type 10 appears to contain a lysine-binding subsite similar to that present in plasminogen kringle 4 , and kringles type 5 to 8 possess a slightly modified LBS. We have therefore suggested that due to kringle-kringle interactions, an increasing number of kringles may render the specific lysine-binding subsite in apo(a) inaccessible to fibrin. Scanu et al. (52) have recently proposed that point mutations in kringle 4 type 10 may occur in humans and that phenotypes with the same number of kringle 4 repeats may be functionally different in terms of their thrombogenic potential; however, their frequency in the general population is very low $(<2 \%)$. Whether the marked variation in apo(a) binding properties is due to the presence or absence of specific kringle sequences or to a variable number of kringles needs further investigation. Taken together, these results suggest that, in addition to the quantitative factor, an important qualitative effect must be considered in the athero-thrombogenic role of $\mathrm{Lp}(\mathrm{a})$.

\section{Binding of $\operatorname{Lp}(a)$ to fibrin and the prediction of $L p(a)$ as a risk factor for cardiovascular disease}

The plasma concentration of $L p(a)$ is determined by genetic factors and remains relatively constant throughout life; dietary changes or lipid lowering drugs have no effect on $L p(a)$. However, $L p(a)$ levels may increase after alcohol withdrawal, in the nephrotic syndrome and during acute phase reactions; also, different hormone-dependent mechanisms may modulate plasma Lp(a) concentration in man. $L p(a)$ levels vary widely among individuals (from $<1 \mathrm{mg} / \mathrm{dl}$ to more than $1 \mathrm{~g} / \mathrm{l}$ ) and among different populations (higher levels of $\mathrm{Lp}$ (a) have been demonstrated in blacks). The definition of a threshold risk value for $L p(a)$ is therefore complicated by such variations and by the methodological problems encountered with the techniques for $\operatorname{Lp}(a)$ determination and with the lability of the $\mathrm{Lp}(\mathrm{a})$ lipoprotein particle (53). However, a so called "normal" level of $L p(a)$ has been arbitrarily assigned using a cut-off point of 20 to $30 \mathrm{mg} / \mathrm{dl}$, most probably based on the highly skewed distribution of $\mathrm{Lp}$ (a) concentration towards low levels in the general population. Based on this value, it has been established that high $\mathrm{Lp}$ (a) concentration is a major independent risk factor for acute myocardial infarction in individuals less than 60 years old $(41,54,55)$. However, a few retrospective (56) and prospective $(57,58)$ studies have failed to detect a correlation between high Lp(a) levels and coronary heart disease. The inadequacy of some test techniques to correctly quantitate $\mathrm{Lp}(\mathrm{a})$, the fact that most subjects are heterozygous for the apo(a) trait and that $\mathrm{Lp}(\mathrm{a})$ particles having a given apo(a) isoform may display varying concentrations, may offer an explanation for these conflicting results. Our findings of an inverse relationship between isoform size and affinity for fibrin, however, raise the hypothesis that the real risk factor is the Lp(a) population with high affinity for fibrin (59). According to this concept, some $\mathrm{Lp}$ (a) phenotypes may not be related to atherogenesis and, therefore, some individuals with high $\mathrm{Lp}$ (a) would not be at risk of coronary heart disease. This new concept of the functional heterogeneity of $\mathrm{Lp}(\mathrm{a})$ adds a new dimension to the evaluation of the predictive value of $L p(a)$ as a risk factor for cardiovascular disease. 


\section{References}

1. Davies MJ \& Thomas A (1984). Thrombosis and acute coronary artery lesions in sudden cardiac ischemic death. New England Journal of Medicine, 310: 1137-1140.

2. Badimon JJ, Fuster V, Chesebro JH \& Badimon $L$ (1993). Coronary atherosclerosis. A multifactorial disease. Circulation, 87 (Suppl II): 3-16.

3. Berg K (1963). A new serum type system in man: the Lp system. Acta Pathologica et Microbiologica Scandinavica, 59: 369382.

4. Beisegel $U$, Niendorf $A$, Wolf $K$, Reblin $T$ \& Rath M (1993). Lipoprotein(a) in the arterial wall. European Heart Journal, 11 (Suppl E): 174-183.

5. Bini A, Fenoglio JJ, Mesa-Tejada R, Kudryk B \& Kaplan KL (1989). Identification and distribution of fibrinogen, fibrin and fibrin(ogen) degradation products in atherosclerosis. Arteriosclerosis, 9: 109121.

6. Smith EB \& Crosbie L (1991). Does lipoprotein(a) Lp(a) compete with plasminogen in human atherosclerotic lesions and thrombi? Atherosclerosis, 89: 127-136.

7. Lawn RM, Wade DP, Hammer RE, Chiesa G, Verstuyft JG \& Rubin EM (1992). Atherogenesis in transgenic mice expressing human apolipoprotein(a). Nature, 360: 670-672.

8. Patthy $L$, Trexler $M$, Vàli $Z$, Bànyai $L$ \& Vàradi A (1984). Kringles: modules specialized for protein binding. FEBS Letters, 171: 131-136.

9. Tulinsky A (1991). The structure of domains of blood proteins. Thrombosis and Haemostasis, 66: 16-31.

10. McLean J, Tomlinson J, Kuang W, Eaton D, Chen E, Fless G, Scanu AM \& Lawn R (1987). cDNA sequence of human apolipoprotein(a) is homologous to plasminogen. Nature, 330: 132-137.

11. Eaton D, Fless GM, Kohr W, McLean J, Xu Q, Miller C, Lawn R \& Scanu AM (1987). Partial amino acid sequence of apolipoprotein(a) shows that it is homologous to plasminogen. Proceedings of the National Academy of Sciences, USA, 84: 3224-3228.

12. Guevara J, Knapp RD, Honda S, Northup SR \& Morrisett JD (1992). A structural assessment of the apo(a) protein of human lipoprotein(a). Proteins, 12: 188-199.
13. Kamboh MI, Ferrell RE \& Kottke BA (1991). Expressed hypervariable polymorphism of apolipoprotein(a). American Journal of Human Genetics, 49: 10631074.

14. Lackner G, Boerwinkle E, Leffert CC, Rahmig T \& Hobbs HH (1991). Molecular basis of apolipoprotein(a) isoform size heterogeneity as revealed by pulsed-field gel electrophoresis. Journal of Clinical Investigation, 87: 2153-2161.

15. Guevara J, Jan AY, Knapp R, Tulinsky A \& Morrisett JD (1993). Comparison of ligand-binding sites of modeled apo(a) kringle-like sequences in human lipoprotein(a). Arteriosclerosis and Thrombosis, 13: 758-770.

16. Anglés-Cano $E$, Rouy $D$ \& Lijnen $H R$ (1992). Plasminogen binding by $\alpha 2$ antiplasmin and histidine-rich glycoprotein does not inhibit plasminogen activation at the surface of fibrin. Biochimica et Biophysica Acta, 1156: 34-42.

17. Anglés-Cano E (1993). The Glu-plasminogen to Glu-plasmin activation pathway at the plasma/fibrin interface. Role of $\alpha 2$ antiplasmin and histidine-rich glycoprotein. Biologia Clinica Hematologica, 15: 99-106.

18. Sugiyama $N$, Iwamoto $M$ \& Abiko $Y$ (1987). Effects of kringles derived from human plasminogen on fibrinolysis in $\mathrm{vi}$ tro. Thrombosis Research, 47: 459-468.

19. Hajjar KA, Gavish D, Breslow JL \& Nachman RL (1989). Lipoprotein (a) modulation of endothelial cell surface fibrinolysis and its potential role in atherosclerosis. Nature, 339: 303-305.

20. Loscalzo J, Weinfield M, Fless G \& Scanu AM (1990). Lipoprotein(a), fibrin binding, and plasminogen activation. Arteriosclerosis, 10: 240-245.

21. Rouy D, Grailhe P, Nigon F, Chapman J \& Anglés-Cano E (1991). Lipoprotein (a) impairs generation of plasmin by fibrinbound tissue-type plasminogen activator. Arteriosclerosis and Thrombosis, 11: 629638.

22. Aznar J, Estellés A, Breto M, España F \& Alos T (1992). Euglobulin clot lysis induced by tissue-type plasminogen activator is reduced in subjects with increased levels of lipoprotein(a). Thrombosis Research, 66: 569-582.
23. Miles LA, Fless GM, Scanu AM, Baynham PJ, Sebald MT, Skocir P, Curtiss LK, Levin EG, Hoover-Plow JL \& Plow EF (1995). Interaction of $L p(a)$ with plasminogen binding sites on cells. Thrombosis and Haemostasis, 73: 458-465.

24. Harpel PC \& Borth W (1992). Fibrin, lipoprotein(a), plasmin interactions: a model linking thrombosis and atherogenesis. Annals of the New York Academy of Sciences, 667: 233-238.

25. Anglés-Cano E, Hervio L, Rouy D, Fournier C, Chapman MJ, Laplaud M \& Koschinsky ML (1993). Effects of lipoprotein(a) on the binding of plasminogen to fibrin and its activation by fibrin-bound tissue-type plasminogen activator. Chemistry and Physics of Lipids, 67/68: 369-380

26. Rouy D, Koschinsky ML, Fleury V, Chapman MJ \& Anglés-Cano E (1992). Apolipoprotein(a) and plasminogen interactions with fibrin: a study with recombinant apolipoprotein(a) and isolated plasminogen fragments. Biochemistry, 31: 6333-6339.

27. Sato $Y$, Tsuboi $R$, Moses $H$ \& Rifkin DB (1990). Characterization of the activation of latent TGF- $\beta$ by co-cultures of endothelial cells and pericytes or smooth muscle cells: a self-regulating system. Journal of Cell Biology, 111: 757-763

28. Kojima S, Harpel PC \& Rifkin DB (1991). Lipoprotein(a) inhibits the generation of transforming growth factor $\beta$ : an endogenous inhibitor of smooth muscle cell migration. Journal of Cell Biology, 113: 14391445.

29. Grainger DJ, Kemp PR, Liu AC, Lawn RM \& Metcalfe JC (1994). Activation of transforming growth factor $\beta$ is inhibited in transgenic apolipoprotein(a) mice. Nature, 370: 460-462

30. Etingin O, Hajjar D, Hajjar K, Harpel P \& Nachman R (1991). Lipoprotein(a) regulates plasminogen activator inhibitor-1 expression in endothelial cells. Journal of Biological Chemistry, 266: 2459-2465.

31. Levin EG, Miles LA, Fless GM, Scanu AM, Baynham PJ, Curtiss LK \& Plow EF (1994). Lipoproteins inhibit the secretion of tissue plasminogen activator from human endothelial cells. Arteriosclerosis and Thrombosis, 14: 438-442. 
32. van der Hoek YY, Sangrar W, Côté GP, Kastelein JJP \& Koschinsky ML (1994). Binding of recombinant apolipoprotein(a) to extracellular matrix proteins. Arteriosclerosis and Thrombosis, 14: 1792-1798.

33. Bihari-Varga M, Gruber E, Rothender M, Zechner R \& Kostner GM (1988). Interaction of lipoprotein Lp(a) and low density lipoprotein with glycosaminoglycans from human aorta. Arteriosclerosis, 8: 851-857.

34. Naruszewicz M, Selinger E \& Davignon J (1992). Oxidative modification of lipoprotein(a) and the effect of $\beta$-carotene. Metabolism, 41: 1215-1224.

35. Haberland ME, Fless GM, Scanu AM \& Fogelman AM (1992). Malondialdehyde modification of lipoprotein(a) produces avid uptake by human monocyte-macrophages. Journal of Biological Chemistry, 267: 4143-4151.

36. Halvorsen S, Skonsberg OH, Berg K, Ruyter R \& Godal HC (1992). Does Lp(a) lipoprotein inhibit the fibrinolytic system? Thrombosis Research, 68: 223-232.

37. Glueck CJ, Glueck HI, Tracy T, Speirs J, McCray C \& Stroop D (1993). Relationship between lipoprotein(a), lipids, apolipoproteins, basal and stimulated fibrinolytic regulators, and D-dimer. Metabolism, 42: 236-246.

38. Williams JK, Bellinger QA, Nichols TC Griggs TR, Bumol TF, Fouts RL \& Clarkson TB (1993). Occlusive arterial thrombosis in cynomolgous monkeys with varying plasma concentrations of lipoprotein(a). Arteriosclerosis and Thrombosis, 13: 548554.

39. Biemond BJ, Friederich PW, Koschinsky $M L$, Levi M, Büller HR \& ten Cate JW (1994). Apolipoprotein(a) attenuates endogenous fibrinolysis in vivo in a rabbit jugular vein thrombosis model. PhD Thesis, University of Amsterdam, 87-97.

40. Palabrica TM, Liu AC, Aronovitz MJ, Furie B, Lawn RM \& Furie B (1995). AntifibrinoIytic activity of apolipoprotein(a) in vivo: human apolipoprotein(a) transgenic mice are resistant to tissue plasminogen activator-mediated thrombolysis. Nature Medicine, 1: 256-259.

41. Rosengren A, Wilhelmsen L, Eriksson E, Risberg B \& Wedel H (1990). Lipoprotein (a) and coronary heart disease: a prospective case-control study in a general population sample of middle aged men. British Medical Journal, 301: 1248-1251.
42. Cremer $P$, Nagel $D$, Labrot $B$, Mann $H$, Muche R, Elster H \& Seidel D (1994). Lipoprotein LP(a) as predictor of myocardial infarction in comparison to fibrinogen, LDL cholesterol and other risk factors: results from the prospective Götingen Risk Incidence and Prevalence Study (GRIPS). European Journal of Clinical Investigation, 24: 444-453.

43. Wald NJ, Law M, Watt HC, Wu T, Bailey A, Johnson AM, Craig WY, Ledue TB \& Haddow JE (1994). Apolipoproteins and ischaemic heart disease: implications for screening. Lancet, 343: 75-78.

44. Schaefer EJ, Lamon-Fava S, Jenner JL, McNamara JR, Ordovas JM, Davis CE, Abofalia JM, Lippel K \& Levy RI (1994). Lipoprotein(a) levels and risk of coronary heart disease in men. The lipid research clinics coronary primary prevention trial. Journal of the American Medical Association, 271: 999-1003.

45. Bostom AG, Gagnon DR, Cupples A, Wilson PWF, Jenner JL, Ordovas JM, Schaefer EJ \& Castelli WP (1994). A prospective investigation of elevated lipoprotein(a) detected by electrophoresis and cardiovascular disease in women. The Framingham Heart Study. Circulation, 90: 1688-1695.

46. Boerwinkle E, Leffert CC, Lin J, Lackner C, Chiesa G \& Hobbs HH (1992). Apolipoprotein(a) gene accounts for greater than $90 \%$ of the variation in plasma lipoprotein(a) concentrations. Journal of Clinical Investigation, 90: 5260.

47. Mölgaard J, Klausen IC, Lassvik C, Faergeman O, Gerdes LU \& Olsson AG (1992). Significant association between low-molecular-weight apolipoprotein (a) isoforms and intermittent claudication. Arteriosclerosis and Thrombosis, 12: 895901.

48. Seed M, Hoppichler F, Reaveley D, McCarthy S, Thompson GR, Boerwinkle E \& Utermann G (1990). Relation of serum lipoprotein(a) and apolipoprotein(a) phenotype to coronary heart disease in patients with familial hypercholesterolemia. New England Journal of Medicine, 322: 1494-1499.

49. Sandholzer C, Saha N, Kark JD, Rees A, Jaross W, Dieplinger $H$, Hoppichler F, Boerwinkle E \& Utermann G (1992). Apo(a) isoforms predict risk for coronary heart disease. A study in six populations. Arteriosclerosis and Thrombosis, 12: 1214-1226.
50. Rouy D, Grailhe P, Nigon F, Chapman J \& Anglés-Cano E (1991). Lipoprotein(a) impairs generation of plasmin by fibrinbound tissue-type plasminogen activator. Arteriosclerosis and Thrombosis, 11: 629638.

51. Hervio L, Chapman MJ, Thillet J, Loyau S \& Anglés-Cano E (1993). Does apolipoprotein (a) heterogeneity influence lipoprotein (a) effects on fibrinolysis? Blood, 82: 392-397.

52. Scanu AM, Liles LA, Fless GM, Pfaffinger $D$, Eisenbart J, Jackson E, Hoover-Plow JL, Brunck T \& Plow EF (1993). Rhesus monkey lipoprotein(a) binds to lysineSepharose and U937 monocytoid cell less efficiently than human lipoprotein(a). Journal of Clinical Investigation, 91: 283-291.

53. Berg K (1994). Confounding results of Lp(a) lipoprotein measurements with some test kits. Clinical Genetics, 46: 5762.

54. Rhoads GG, Dahlen G, Berg K, Morton NE \& Dannenberg AL (1986). Lp(a) lipoprotein as a risk factor for myocardial infarction. Journal of the American Medical Association, 256: 2540-2544.

55. Sandkamp M, Funke $H$, Schulte $H$, Kohler E \& Assmann G (1993). Lipoprotein(a) is an independent risk factor for myocardial infarction at a young age. Clinical Chemistry, 36: 20-23.

56. Haffner SM, Moss SE, Klein BE \& Klein R (1992). Lack of association between Lp(a) concentrations and coronary heart disease mortality in diabetes: the Wisconsin Epidemiologic Study of Diabetic Retinopathy. Metabolism, 41: 194-197.

57. Ridker PM, Hennekens $\mathrm{CH}$ \& Stamper MJ (1993). A prospective study of lipoprotein(a) and the risk of myocardial infarction. Journal of the American Medical Association, 270: 2195-2199.

58. Jauhiainen $M$, Koskinen $P$, Ehnholm $C$ Heikki Frick M, Mänttäri M, Manninen V \& Huttunen JK (1991). Lipoprotein (a) and coronary heart disease risk: a nested casecontrol study of the Helsinki Heart Study participants. Atherosclerosis, 89: 59-67.

59. Anglés-Cano E, Hervio L \& Loyau S (1993). Relevance of lipoprotein(a) in cardiovascular disease: methodological approaches. Fibrinolysis, 7 (Suppl 1): 66-68. 